\title{
Creating Shared Value
}

\author{
Arpie Balian \& Astghik Ghevondyan \\ American University of Armenia, Yerevan
}

Received 2 July 2018 - Revised 24 July 2018 • Accepted 31 July 2018

\begin{abstract}
This research investigates how shared value can be created when both public and private organizations collaborate at various fronts. Particular attention is paid on how public-private collaboration would develop through discussions and open communication between government and business so as to contribute to building interest in the strategic development agenda of a state and lead to the adoption of mechanisms that create shared value for government, business, and society. The findings reveal that constructive dialogue and regular discussions could lead to better understanding the priorities of both government and society, to finding common ground for resolving social problems and for adopting a shared agenda through which value is created for all. The lead responsibility rests on government to take initiative for dialogue with business and society, to establish policies that are conducive to business development, and to provide incentives for public-private partnered solutions to public problems. Also, business must shift its classic way of profit-maximization strategy and not view government as merely regulator, but as partner with whom mutually beneficial results can be attained.
\end{abstract}

Keywords: shared value, public-private collaboration, constructive dialogue, shared agenda, business action for society.

\section{Background}

Before the second half of the twentieth century, governments and, to a lesser extent, non-profit organizations were regarded largely responsible for solving societal problems. The role of government was more that of regulator and not as much that of provider of public services, safety and security. Changes in the role of government were influenced by neo-liberal and democratic theorists starting with Friedrich (1944) but gradually more intensely with Moore (1995), Bozeman (2002) and others who placed emphasis on the role of government as creator of public value. In that context, the role of non-profit organizations took on different portrayals that centered on collaboration and partnership for value-added outcomes for society.

In line with changes in the public sector, starting in 1950 s and 1960s, the concept of corporate social responsibility (CSR) emerged in the form of corporate philanthropy and referred to "the obligations of businessmen to pursue those politics, to make those decisions, or to follow those lines of actions which are desirable in terms of the objectives and values of society" (Bowen, 1953: 6). Strategies and programs that private enterprises considered under CSR were rather superficial at times and were primarily directed to increasing their business reputation,

(C) Authors. Terms and conditions of Creative Commons Attribution 4.0 International (CC BY 4.0) apply. Correspondence: Arpie Balian, Professor, American University of Armenia, Yerevan, ARMENIA. Email: abalian@aua.am. 
market share and profit. Many viewed CSR as a necessary expense to complement advertising and promotion efforts.

Subsequently, the notion emerged in discussions of corporate culture and values that employees ought to embrace (Schein, 1985; Amsa, 1986; Stubbart, 1988; Chatman \& Cha, 2003). The leading definition of "corporate value" was proposed to mean "organizational values [that] make a significant difference in the lives of employees, as well as in ... performance" (Posner et al., 1985). This could be interpreted as an organizational strategy for aligning corporate vision and goals with those of individual performance goals and objectives; for increasing ownership of corporate values by employees; and for increasing productivity and profits. By the turn of the century, the understanding of shared value evolved to establish new meaning as business "policies and operating practices that enhance competitiveness ... while simultaneously advancing the economic and social conditions in the communities in which it operates" (Porter \& Kramer, 2011: 66). This definition is broader than CSR in that it incorporates business and society interactions and adoption of shared agenda for action.

This study attempts to integrate "public value" and "shared value" through linkages among government, business and society. Particularly, it answers the question of how shared value is created at the state level when public and private organizations cooperate on various fronts. Drawing on the cooperative models and processes relevant to the private sector, how would public-private dialogue and strategic collaboration create "shared value" for government, business, and society? Considering that the theory of "shared value" is progressively taking on more importance, this study attempts to analyze concepts that have benefited government, business and society in order to identify or underscore those factors that are the most influential in fostering development.

\section{Creating shared value for growth}

The theory of shared value claims that economic values can be created by addressing societal needs thereby creating value for society. Applied to the private sector, addressing the needs of society would lead to business success. Thus, the success of a company and social development are interdependent. When a business operates on the principle of creating shared value, gaps between society and business diminish, and the latter is elevated by society and accepted as a legitimate enterprise. In that process, business takes into account societal needs through a process that creates value or positive impact, which is transferred to or shared with society.

However, in order to create shared value, profit chasers had better think in new ways, restructure internal practices and cooperate across sectors. Considering new ways of doing business, scholars posit that shared value initiatives could transform capitalism and initiate new connections between business and society. Moreover, the theory of shared value is applicable to both developing and developed countries even though particular areas of common interest and mechanisms may vary among countries (Lenssen et al., 2012; Porter \& Kramer, 2011; Pol Longo et al., 2005). Along those lines, Porter and Kramer (2011: 7) identify three ways of creating shared value: "Reconceiving products and markets, redefining productivity in the value chain and building supportive industry clusters at the company's locations."

As such, the process of creating shared value entails first identifying the kinds of societal needs and problems that exist, government programs that tackle those needs, unmet issues, and potential economic opportunities that could be created through solving those unmet and persistent public needs. When business and government partner to undertake specific actions for solving public problems, this creates new opportunities for business and new value 
for society. Thus, positive outcomes created in one sector are transferred to other sectors and to the broader public (Porter \& Kramer, 2011).

Moreover, increasing the speed of development requires public and private sectors to work together within a strategic partnership framework set to implement shared value initiatives in support of the state development agenda. This would place the creation of shared value at the center of development generating collaboration around common goals and reducing social inequalities in health, education and other public services. Within an environment of collaboration in support of shared public goals, businesses continue to strive for profits, but also take responsibility for solving societal problems along with government or partially shouldering the role of government to create public value. This would enable governments to reach development goals more rapidly provided state budgetary resources are allocated for achieving partnered targets and shared value strategies (Pol Longo et al., 2005).

Moreover, when governments adopt policy instruments or regulatory mechanisms that inspire and encourage private entrepreneurs to incorporate the principle of shared value into core business strategies, value-producing trade-offs among social objectives and economic gains are made possible. Thus, the phenomenon of creating economic value by addressing societal needs becomes more feasible and leads to faster development (Porter \& Kramer, 2011). In this regard, Prato (2013) argues that when lead actors in the public and private sectors unite forces and work towards mutually beneficial solutions, they serve as models for other businesses to also align their business goals with public needs. Moreover, he identifies a number of factors that contribute to productive public-private partnerships, two of which are given added importance: establishing a shared agenda and well-defined incentives for all partnered sides. Thus, from the perspective of the private sector, resolving public issues should not be viewed as doing philanthropy, but as business opportunity. In this context, Borgonovi et al. (2011) argue that since government alone does not have enough resources to solve all societal needs, working closely with business is significant to creating mutual benefits for both government and society.

\section{Establishing government-business dialogue}

For the business sector, adopting the principle of shared value is a creative approach for finding new business prospects and helping the government cope with social issues that hinder development. There is a viewpoint that when the private sector does not recognize that business achievements are closely correlated with social results, it fails to achieve long-term positive outcomes (Porter et al., 2011). But who is to guide private enterprises to view social issues as new business opportunities?

Longo et al. (2005) argue that government should contribute to the process of creating shared value and boost the social impact generated by the business sector. For this purpose, government should engage businesses in constructive dialogue about the possible ways in which companies could help the government to achieve development goals while advancing their own business interests. Moreover, not only governments, but also non-governmental, multilateral and community service organizations could bring the private sector into regular discussions on the most important social issues and jointly find possible approaches to resolving or preventing them.

When governments fail to promote investments that support business development, they lose such important instruments as the power of influence on the business sector. Only by engaging the private sector into productive dialogue it becomes possible to create an environment where the business sector takes a path of looking into social issues as attractive business opportunities. Moreover, only by diagnosing social problems in productive dialogue it 
becomes possible to accelerate the process of achieving state strategic goals and amplifying social change through the participation of business.

Establishing constructive dialogue serves as catalyst for creating public-private partnerships. As Herzberg and Wright (2005) argue, only when the public sector understands how the private sector works and what it needs, it will be able to establish policies that benefit both. In turn, as the private sector becomes better aware of the priorities of government and engages as partner in working toward state priorities, it will then be ready to support government in achieving its goals. Continued dialogue and discussion between public and private facilitate the process of finding alternative policy solutions but also lead to a higher probability of success. Thus, an environment of mutual support, trust and consideration between public and private stimulates the implementation of policies and programs that create shared value.

\section{Research design and methodology}

The study uses a qualitative methodology with an explanatory research design aimed at analyzing discourse to map out the most relevant strategies and arrangements for creating shared value. Inductive reasoning is used to draw a model from dominant patterns found in the collected data. The study uses in-depth interviews with select leaders in the public and private sectors in the Republic of Armenia to measure the level of interest in and compassion for collaboration, as well as to understand the level of readiness for making a sustainable paradigm shift in this realm. The questions steering the data collection relate to how shared value is created and how public-private collaboration contributes to shared value creation. The qualitative approach has made possible the collection of rich sets of data from the interviews affording an understanding of the different positions on the concept of "shared value".

Purposive sampling was used in selecting the interviewees to allow for maximum variation of data collected. Twelve (12) interviews were conducted in February-April 2018 with key actors from both public and private sectors. The interviewees included officials from the RA Ministry of Economic Development and Investments, particularly with heads of units responsible for tourism development and investment policy; the Centre of Strategic Initiatives of Armenia; top management of the RA Ministry of Health; representatives of leading companies in telecommunication, banking, insurance, dairy and wine companies; and subject matter experts. The interviewees focused on their respective sectors and sub-sectors, the current state of development and how they envision public-private collaboration.

As mentioned earlier, the study uses inductive analysis to draw a model that depicts mechanisms for creating shared value as opined by the interviewees. It is proposed that building high levels of social capital leads to dynamic collaboration between government and private sector entities. The study addresses how shared value is created and how public-private collaboration contributes to the dynamic progression of that effort. It is also assumed that establishing persistent working relations between government and business leads to adopting a shared agenda and value platform thereby creating shared value for all.

\section{Data analysis and discussion}

\subsection{Analysis of in-depth interviews}

The analysis of interviews ( $n=12)$ focused on identifying the most critical building blocks required for realizing "shared value" to produce the best outcomes for business and society. In the first instance, the interviews explored the prerequisites of public-private 
collaboration and moved on to understand the level of prevalent openness among public and private organizations for making the necessary paradigm shift in this domain.

The dominant theme in the interviews was that government and business should first identify common interests and potential platforms that would bring them together to engage in collaborative decision-making to achieve mutually beneficial solutions. The more the sectors come together to reach a shared understanding of public problems, the more the chances of adopting collaborative approaches to solving those problems through actions that benefit all parties and deliver added value to society. In that context, one interviewee explained that "if government and business were able to find common interests in solving public problems, mutual benefits would be created for all - government, business and society."

Many interviewees (6/12) are of the opinion that productive and mutually beneficial working relations between government and business start with instituting constructive dialogue between them. In order to engage in cooperative arrangements, private enterprise should feel that it is an integral participant in the process of solving public problems. As was articulated by one interviewee, "... in order to establish focused working relations between government and business, it is necessary to hold regular discussions on mutual concerns and openly deliberating public needs." Only by coming together and discussing issues would political actors and entrepreneurs gain a better understanding of public needs and grasp their relative criticality.

Moreover, in the absence of constructive dialogue the gap between state agenda and business interests widens, as maintained by several interviewees. One specifically argued that "frequently business does not even understand how government works and in what strategic direction it is going." The same also is true for the other. In most cases government is unaware of the mindset and issues prevalent in the private sector and, conversely, business does not have a grasp of critical public issues so as to be able to take action in mutually beneficial ways that create shared value.

Moreover, four government representatives interviewed stated that if government gets a handle on the major concerns of private enterprise it will be able to develop policies conducive to growth. As mentioned by one interviewee, "... if the private sector were to make more effort in presenting and explaining to government the major issues that they face, we would be in a better position to draft policies that are favorable to growing private enterprise in Armenia." Through regular dialogue, common private and public interests and concerns would be identified thereby establishing top priority areas for all regardless of the diversity of issues and preferred solutions. By adopting a shared value platform, public and private sectors could together reach workable solutions on critical issues that would result in benefits for all.

Another factor emphasized by the interviewees from private enterprise was the relatively high degree of readiness to engage with government in collaborative arrangements provided their business position is not undermined. As one interviewee articulated, "many businesses would be readily motivated to cooperate with government and other public agencies provided such cooperation is based on just grounds and fair principles. Also, the important condition here is that the solution fundamentally aims at realizing shared goals and is derived from constructive and sustained dialogue among various businesses from different sub-sectors, as well as between the private sector and government." This suggests that the private sector would undertake solving social issues when they see in it business gain, such as increase in market share, product advantage and satisfaction, or economic profit. According to one respondent, "the overarching purpose of any business enterprise is to maximize profit. Businesses usually pursue filling public demand for goods and services such that they increase satisfaction thereby retaining or increasing market share. Aside from that, businesses would be interested in solving social problems provided action in that regard does not create barriers to realizing their business strategies and fulfilling their planned targets. More, this would 
enable connecting the needs of society with business success.” In contrast, philanthropy would not create sustained business advantage.

Several respondents (4/12) from the public sector also raised the need for not looking to government as simply a source of financing or subsidy for achieving mutually beneficial solutions. One interviewee stated that “... for a long time the business sector has looked at government as purely a resource from which to draw technical or financial assistance. This mindset should be changed. The private sector should consider projects that consider working with the public sector toward achieving shared goals instead of consistently looking for monetary or other types of assistance from government to benefit their business." It is possible, they claim, to establish effective working arrangements between government and the private sector when the latter begins focusing on public needs and preferences aside from focusing on profit-making priorities and, together with government, it aims at generating public value for society.

The factor of identifying common interests and platforms was mentioned most frequently by the interviewees from both public and private sectors. The most important requirement for engaging in cooperative agreements and connecting the needs of society for business success is identifying common interests and platforms. Only when business and government find common interests, they will be able to establish focused working interrelations and adopt a shared agenda for achieving mutually beneficial outcomes. As elaborated by one interviewee, "each approach directed to establishing effective or constructive cooperation usually moves toward finding win-win interests. ... And that is good! Similarly, at the state level, identifying and nurturing shared interests and platforms is the most important factor for establishing focused working relations between government and business." The idea behind this argument is that the main purpose of business is to derive as much revenue and profit as possible, whereas the main purpose of the public sector is to solve as many social problems as possible. Government has the added mandate to deliver public goods and services efficiently, effectively, and equitably. That is why only in those cases when government and business are able to hold constructive dialogue and find mutually beneficial solutions they will be able to work together toward achieving shared value.

Further, the issue of maintaining focus on public priorities, critical needs and preferences was pointed out by all the interviewees representing government. They emphasized that when discussing common concerns with the private sector, there should be added focus on public preferences. After all, no less than the public sector, the business sector also should make every effort to meet public demand, focusing on preferences vis-à-vis products. When the private sector keeps all that in mind and also collaborates with government to keep abreast of strategic public priorities, the country is able to achieve win-win results. In line with this argument, several interviewees $(5 / 12)$ indicated that government should be in a position to identify and/or determine the strategic priorities of the public and assume a leading role in linking the needs of society for business success.

As one interviewee articulated,

"Governments should identify the areas that would stimulate business interests while presenting a relevant action point in the government's strategic agenda. Based on that, government should take initiative in getting the attention of businesses onto those public issues that need most attention and/or inviting businesses from respective industries or sectors for dialogue on those issues."

Another interviewee added,

"The only way of motivating the private sector to take interest in public needs and take part in delivering optimal solutions is to motivate businesses to look to social issues from an innovative standpoint. This will not only lead to solving social 
issues but also will push development forward and make the private sector more robust."

However, in order to be able to find appealing prospects for solving social problems with a business perspective, the specific problems should be better understood by all, but especially by business; this suggests that the government should assume a leading role in connecting the pressing or more important social problems with business. In that regard, government should partner with the private sector in defining unmet public issues to jointly define and analyze the level of criticality of those problems making information transparent to both sectors and to the public at large. The transparency of the process is critical to preclude or dismiss any impression or perception of corruption, including decisions related to possible solutions and inclusion of such actions in the national development agenda and strategic plan. The idea in support of this argument is that when businesses have a clear understanding of the unattended social problems and are apprised of the segments of society affected by those problems, they would be in a better position to propose innovative solutions that also fall within their business strategies.

Furthermore, government should develop and promote policies conducive to business development that will simultaneously connect the needs of society for business success. After all, this also would help grow the private sector, especially the small and medium-size enterprises, which in turn would help develop the economy and increase the middle class (elements very crucial for moving developing countries forward). As one of the interviewees mentioned "the government should set up a clear strategy that will unify the interests of business, government and society." In the same line of thought another interviewee brought up that "government should identify the most critical public goods and avail businesses with such vital information that are bound to stimulate new interest in the private sector and bring together government and business to work together for achieving the state development agenda." Another interviewee added that

"The single most essential element in government-business collaboration leading to development lies in establishing focused working relations between government and business from relevant respective domains. Only by engaging in constructive discussion and sustained dialogue would it be possible to reach agreement that produces collaborative arrangements between government and business for solving public problems."

Concerning the critical success factor of promoting policies that are conducive to business development, four interviewees (4/12) emphasized that government has the principal responsibility for creating shared value. In that context, when developing policies, rules and regulations, government should take into account the major issues prevalent in the business sector and look to alternative solutions to those issues while simultaneously attracting businesses to collaborate in addressing public needs.

Another factor that was emphasized by three interviewees (3/12), all three being from the private sector, was the key reason that keeps the private sector interested but not engaged in solving social issues is driven by their own operational budgets and revenue targets. Although the business sector may project additional revenues from solving a specific social issue, they often do not commit because of the business risks involved. If the business sector were to have confidence in government support, it would work more seriously with the government to achieve mutually beneficial solutions. 


\section{Findings and conclusion}

The discourse analysis of and findings from the in-depth interviews afforded the information necessary to construct a model of how shared values are or can be created. The collected data helped validate the assumptions embedded in the theory of Creating Shared Value according to which economic values are created by addressing societal needs thereby creating value for society (Porter \& Kramer, 2011). The analysis also showed that the critical element necessary for creating shared value at the state level is the identification of common interests and platforms and adopting a shared agenda. This finding is identical with the argument brought by Longo et al. (2005), which states that for optimal results in development, public and private sectors should strive to work together in order to achieve mutually beneficial solutions.

Likewise, the data analysis revealed that establishing constructive dialogue between government and private enterprise is critically important for identifying a common platform and interest that leads to adopting a shared agenda. This will lead to establishing focused working relations between public and private sectors and to creating shared value while promoting the process of development throughout the country. This finding is supported by the argument by Borgonovi et al. (2011), which claims that government alone does not have enough resources to solve all societal needs.

Moreover, the analysis of interviews disclosed the fact that solving social issues with an innovative business perspective is one way of achieving mutually beneficial solutions for government, business and society. This finding corresponds to the viewpoint discussed in the literature according to which solving social issues from a business perspective is a way of addressing societal needs in a participatory manner, such that the positive impact created by business is transferred to society.

The interviews revealed that in order to be able to achieve mutually beneficial solutions there is a need to establish focused and strategy-driven working relations between government and private business. When public and private sectors have common interests they would be more interested in working together in order to achieve mutually beneficial solutions. However, in order to establish focused working relations between government and business, both should come together in constructive dialogue centered on the purpose of resolving public problems or unmet needs. Moreover, through sustained dialogue common indicators are created for understanding social problems and for adopting an agenda that creates value for all.

In addition, the study showed that at the current stage of Armenia's development, the lead role still rests on the government to create opportunities for connecting business and society while establishing policies that are conducive to

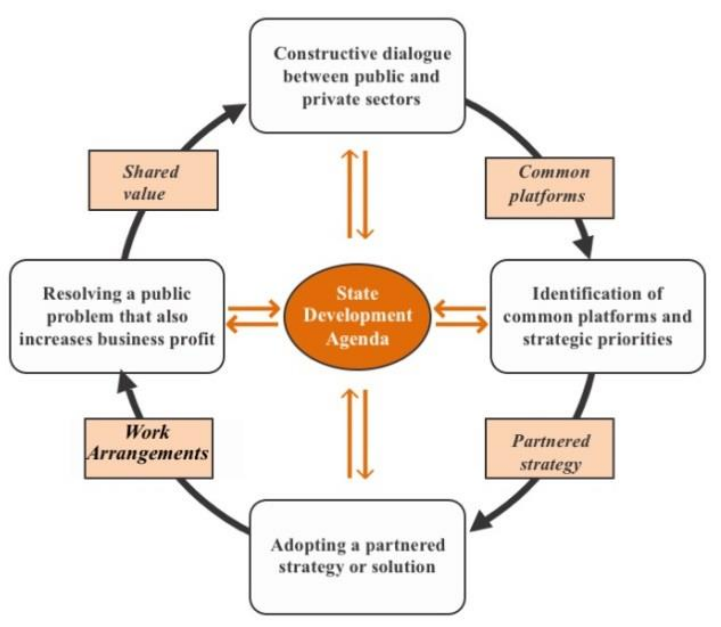
private sector growth. However, congruent to the argument brought by Porter and Kramer (2011), the analysis revealed that business has to shift its classic way of thinking restructuring its internal policies and not looking to government as merely a regulator, or a source of financing and subsidies, but as a partner with whom mutually beneficial goals can be realized. 
No doubt, the only possible way for achieving development goals for a country with limited human and social capital requires joining forces and putting to optimal use the strengths of both public and private sectors. Working closely and strategically, government and business would be able to achieve mutually beneficial outcomes, which will improve the quality of life while advancing the national development agenda. Such mechanisms hold promise for economic growth and sustained development. As argued by Longo et al. (2005), public and private sectors should work together toward achieving shared goals and moving forward the national development agenda.

Thus, this research confirmed the assumptions stated in the theory of shared value put forth by Porter and Kramer (2011), according to which economic values are created by addressing societal needs thereby creating value for society. Sustained dialogue between government and business was found to be a prerequisite to adopting a shared development agenda. As the proposed model shows, only through sustained dialogue and discussions around the state development agenda can priority public needs be resolved through partnered arrangements between government and business operating in relevant domains. As stated by Herzberg and Wright (2005), continued dialogue and discussion would not only facilitate the process of finding mutual platforms and strategies for economic development, they also would make possible the successful implementation of policies because of the transformed perception by the private sector of being a part of policy decision-making. Thus, an environment of mutual support, trust and reciprocal consideration between public and private sectors makes possible the implementation of policies and achievement of developmental goals. Above all, mutual trust between government and business transcends all other priorities in this domain as much as in others. Moreover, as indicated by Borgonovi et al. (2011) in the current age of development it is possible to solve social problems and to maintain equilibrium of economic and social benefits only in those cases when government and business have established mutual trust and cooperate on a sustainable basis.

\section{Acknowledgements}

This research did not receive any specific grant from funding agencies in the public commercial, or not-for-profit sectors.

The authors declare no competing interests.

\section{References}

Amsa, P. (1986). Organizational culture and work group behaviour: An empirical study. Journal of Management Studies, 23(3), 347-362.

Borgonovi, V., Meier, S., Sharda, M., \& Vaidyanathan, L. (2011). Creating shared value in India: How Indian corporations are contributing to inclusive growth while strengthening their competitive advantage. Retrieved January 2018, from www.sharedvalue.org.

Bowen, H. R. (1953). Graduate education in economics. American Economic Review, 43(4), iv-223.

Bozeman, B. (2002). Public-value failure: When efficient markets may not do. Public Administration Review, 62(2), 145-161.

Chatman, J. A., \& Cha, S. E. (2003). Leading by leveraging culture. California Management Review, 45(4), 20-34. 
Friedrich, A. (1944). The road to serfdom. Chicago: University of Chicago Press.

Herzberg, B., \& Wright, A. (2005). Competitiveness partnerships: Building and maintaining public-private dialogue to improve the investment climate. A resource drawn from the review of 40 countries' experiences. World Bank Policy Research Working Paper.

Lenssen, G., Van Wassenhove, L., Pickard, S., Lenssen, J.-J., Spitzeck, H., \& Chapman, S. (2012). Creating shared value as a differentiation strategy - The example of BASF in Brazil. Corporate Governance: The International Journal of Business in Society, 12(4), 499-513.

Moore, M. H. (1995). Creating public value: Strategic management in government. Harvard University Press.

Pfitzer, M., Bockstette, V., \& Stamp, M. (2013). Innovating for shared value. Harvard Business Review, 91(9), 100-107.

Pol Longo, M., Mura, M. \& Bonoli, A. (2005). Corporate social responsibility and corporate performance: The case of Italian SMEs. Corporate Governance, 5(4), 28-42.

Porter, M. E., \& Kramer, M. R. (2011). The big idea: Creating shared value. Harvard Business Review, 89(1), 2.

Posner, B. Z., Kouzes, J. M., \& Schmidt, W. H. (1985). Shared values make a difference: An empirical test of corporate culture. Human Resource Management, 24(3), 293-309.

Prato, S. (2013). A new global partnership with business. Business Action for Africa, Harvard Kennedy School.

Schein, E. H. (1985). Increasing organizational effectiveness through better human resource planning and development. Readings in Human Resource Management, 376.

Stubbart, C. I. (1988). Power and shared values in the corporate culture. JSTOR. 